\title{
Globalization and the Future of Sociology in the Third World: A Critical Commentary ${ }^{1}$
}

\author{
Israel Dantata Sule \\ Department of Sociology \\ Ahmadu Bello University, Zaria \\ israelsule@vahoo.com
}

DOI: $10.36108 / \mathrm{NJSA} / 8002 / 60(0130)$

Vol. 6 Issue 1, 2008

\begin{abstract}
Beginning from the 1980s, the concept of globalisation began to permeate the sociological literature. This intellectual interest was stimulated by a concern to understand the nature of changes that were taking place in advanced capitalist societies and Third World countries. The seemingly homogenous atmosphere it created across the globe made certain sociologists, such as Archer, Heller and Sztompka, just to mention a few, opined that every major aspect of social reality is also simultaneously undergoing globalisation via the emergence of a world economy, a cosmopolitan culture and international social movements. Hence, they concluded that the globalisation of society means that societies were no longer the prime units of Sociology and that what is to replace this focus on societies is a 'Sociology of one World' in which global processes are now constitutive of social reality everywhere. They equally asserted that sociologists can no longer continue to think, theorise and carry out research as they once did. Thus, this paper highlights and critically comments on this position and how it is likely to impact on the sociological enterprise in the Third World. The paper concludes on the note that the Sociological enterprise in the Third World must be carried out to meet needs that are localised and indigenous.
\end{abstract}

Key words: globalisation, universal sociology, neo-liberal, single world society.

\section{Introduction}

Without gainsaying, the entire globe and humanity is living in the era of intensified globalisation: a process marked by accelerated flow of goods, services, capital, images, knowledge, fashion, labour, etc. through electronic information and communication, electronic transfer of large funds across boarders, greater and closer relationship and unprecedented interdependence among nations like has never been witnessed at any historical epoch of human existence. So impacting is the phenomenon in the re-ordering of time and space in social life that Giddens refers to the process as "time-space distanciation"

\footnotetext{
${ }^{1}$ This paper was originally presented at the National Conference on Social Dimension of Reforms and Development, organised by the Nigerian Anthropological and Sociological Association (NASA), at the Uthman Dan Fodiyo University, Sokoto, August 20-22, 2008.
} 
(1990:14). Harvey, likewise labels it as "time-space compression" (1989:240). The emergence of global systems of production and exchange, which is predicated on neo-liberal doctrine of economics, orchestrated and facilitated by the triumph of western liberal capitalism in the aftermath of the cold war among other factors, is seen to be responsible for this.

The rapidity with which events flow across the globe a lot of times diminishes the grip of local circumstances over people's lives and further shapes their social relations in a new way. For example, the final pricing of petroleum at the local market in Italy or America to the final consumers may be more dependent on the activities of youths in the Niger Delta area of Nigeria than upon the immediate decisions of local managements in those countries. In Gidden's view, this kind of social relations that is occurring contemporaneously should be associated with the forces of modernity. To him, globalisation expands the scope of such processes; with the consequences that larger and larger numbers of people live in circumstances in which institutions link local practices with globalised social relation and shape major aspects of day to day life (see Giddens 1990). The implication of Giddens' view is that in today's world, social relations and interactions are not dependent upon simultaneous physical presence within a specific location, rather it depends on the structures and institutions of modern societies which are facilitated by instantaneous communication. This fosters intense relations among peoples and nations that are locationally distant from each other, more than any given situation of face to face interaction or geographical contiguity.

Thus, if globalisation has made so much impact on the socio-economic, socio-spatial and political milieu of peoples and nations, does this not suggest the need for universal account of social affairs, and by extension the emergence of universal truths? Does globalisation not bring into question the redefinition of fundamental and foundational concepts such as 'society', 'social interaction' and the entire purview of sociology: that is, the understanding of and precise interpretation of social reality, which still occupy a privileged position in the discourse of this field of knowledge.

Based on the above questions, certain sociologists such as Archer, Heller, Sztompka, Tiryakian and Bauman have called for the universalisation (also referred to as internationalisation) of sociology because of their belief that we now live in a single 'world- society'. According to them, this 'world society' is characterised by homogeneity of culture, world economy that is under-guarded by neo-liberalism, a global political space that is structured and grounded on democratic principles and procedures and a global order that is continuously and increasingly leading to a 'borderless world' in which nation states are declining and are being replaced by regional institutions such as European Union (EU) and International Financial Institutions (IFI's). According to Archer:

Each major aspect of social reality (the structure, culture and personality of traditional terminology) is simultaneously undergoing globalisation...hence... sociologists have to respond to the challenge 
by conceptualising this novel transformation and theorise about it in new ways (1990:1).

Contrary to the argument that globalisation positively affects every aspects of human endeavour including ones perception and contemplation of social reality, this paper contends from a Third world perspective, that this kind of orientation that is being introduced to the field of sociology especially from the American/European brand of scholarship is inimical to the growth and relevance of the discipline to the developmental challenges of the Third World. The idea that globalisation of consciousness and knowledge now exist to the extent that sociologists should no longer think or theorise as they once did is misleading and spurious. The growing inequalities of wealth and opportunities arising from globalisation, and the perception that environmental, social and cultural problems have been made worse by the workings of the global freemarket economy attest to this.

The paper is organised into four sections including this particular segment which is a brief introduction of the thrust of the paper. The second section presents a summary of the position of the proponents of a universal sociology. The third segment is a critique of this position in light of socio-economic and political developments in the Third World countries in a so-called globalised world. Finally, section four draws general conclusions and suggestions hinged on the note that while Third World Scholars must keep abreast of global trends of events, the sociological enterprise must be highly nationalised and localised, in order for it to meet the desired expectation of Third World societies.

\section{Globalisation and the Call for a Universal Sociology: A Summary of Discourse}

Though the call for a universal sociology harbours a wide range of contribution from several scholars, the summary here is largely based on the writings of Archer, Heller, Sztompka and Tiryakian on the same subject matter as contained in the edited works of Albrow and Kings (1990), Globalisation, Knowledge and Society. The choice of their writings as the platform for this paper is because their works essentially served as somewhat of a magnum opus which several other scholars have always made reference. Thus their writing is a good representation of the principal assumptions of this line of contemplation. They foreground the call for universal sociology in their definition of globalisation as all those processes by which the people of the world are incorporated into a single world society. They also claim that each major aspect of social reality (the structure, culture and personality of traditional terminology) is simultaneously undergoing globalisation, as witnessed by the emergence of a world economy, a cosmopolitan culture and international social movements.

According to these scholars, Sociologists should respond to the challenges of globalisation by conceptualising, theorising and interpreting social reality in new ways that are logically consistent and in tandem with global occurrences, 
hence they advocated for a single sociology whose ultimate unity rests in and acknowledges the universality of human reasoning, the unity of humanity and the endorsement of a single world whose oneness is based upon the adoption of a realistic ontology. According to them, this should be the starting point of modern sociological enterprise.

The proponents of universal sociology opined that relativism of concepts, percept, truth and logic should be jettisoned by sociologists because it breeds 'other minds' that buttress and encourage ethnocentrism in intellectual scholarship. According to Archer, "relativism...has always been the...Scylla on which the sociological enterprise could flounder: other minds and other worlds are the implacable enemies of international sociology"(1990:2). Furthermore, they posit that societal meanings and concepts entertained by people of varied background have undergone far reaching uniformisation and have become more alike due to the impact of mass flow of information through the media, tourism, travels, personnel contact, etc. According to them, local, national or regional specificity of concepts are becoming ever more tenuous and are gradually being replaced by unifying interpretation of events. In pursuit of this line of thinking, Sztompka asked the question "what happens to sociological meanings and theoretical concepts used by sociologists in such an expanding ... milieu?" He answered, (erroneously though) that they also pass through the process of uniformisation and homogenisation of perspectives (Sztompka 1990:48). They also posit that modern Sociology should equally transcend cultures just as the universality and relevance of natural science; mathematics and logic could not be affected or explained by reference to anything about the specific cultures in which they were adopted.

Since sociology's master-concept, society, as the basic unit of sociological analysis is no longer a useful conceptual tool, the need to reconstruct sociology in global terms has become imperative. In order to achieve this, Tiryakian (1990) adopts Gerhard Leski's proposal where he stated that there are three major types of sociological study. These are:

- Macro sociology which encompasses the study of total societies and of the world systems;

- Micro sociology which concerns itself with studying the impact of societies on the individual; and,

- Meso sociology which covers the study of one's owns society and its institutions.

With emphasis on the macro sociology, he opined that this sociology should be concerned with the structure and dynamics of relations between clusters of countries (such clusters should have certain collective identity, political, cultural or otherwise) and ultimately with relational structures between clusters tending in the modern period to develop into one broad interrelated global system. The aim of this macrosociology should be to deal 
with large-scale social phenomena and their global interdependence and manifestation. Since Tiryakian's proposal, there have been hoards of such proposals, such as the ones by Beynon and Dunkerley (2000), Cohen and Kennedy (2000) and Held (2000).

\section{Globalisation, Universal Sociology and the Third World: A Critical Commentary}

As a matter of fact, the vision to universalise sociology as a discipline had always been at the heart of the founding fathers of sociology in their attempt to explicate human interaction and the challenges that ensue from such interaction. In order to achieve this, they equated the social world with the natural world and adopted the application of Natural Science Modus operandi of investigation to social occurrences with the aim of developing universal laws for understanding and predicting the future of society. They frowned at subjectivism and relativism and promoted universalism in the analysis and interpretation of social reality (see Durkheim's Rules of Sociological Method, 1938). The ubiquity of their assertions, theories and universal laws began to lack the ability to explain other cultures, immediately it came in contact with non-Western societies. Alatas affirms this when he said that there is a strong awareness within academic circle in third world countries that there is "lack of fit between Western social sciences and non-Western realities" (2002:15). With specific reference to Nigeria, Nkom (1993:197) lamented that:

Questions have naturally arisen concerning the relevance and applicability of the alien social sciences to the realities, challenges and aspirations of Nigeria. To what extent do the concepts, theories and methodologies of this imported social science reflect the social and cultural realities of Nigeria? To what extent can its theories and paradigms accurately explain the problems and predicaments of the Nigerian society.

It was this dilemma that made Akiwowo (I do not wish to join issues with those who are opposed to his proposition, see Lawuyi and Taiwo, 1990; and Adesina, 2000) proposes that the social sciences be indigenised or domesticated such that they reflect and capture the realities, thought-processes and indigenous world-views of Nigerian and third world societies (Akiwowo, 1988; Nkom, 1993; Sule, 2006).

Therefore, the call for a universal sociology (see Wallerstein, 1990; Gulbenkian Commission Report, 1996; Archer, 1990), is not only flimsy, narrow and parochial, it is equally and subtly hegemonic in nature. It is certainly a re-branding of the imperialistic tool (called positivism) of western capitalist order for the continuous subjugation of non- western societies. According to Adesina (2002:258), "The unicity of humanity that requires that we have a single discipline for a single world...assumes that the dominant traditions in western sociology can speak for the global community of 
sociology...the international endeavour within sociology is one that has advanced not because of its universality but as... an imperial agenda that has been called the 'triumph of the West". The 'single humanity', that Archer pitches for assumes its 'unicity' by denying a voice to the non-western voices. (And the non dominant voices in the west, as well).

A critical examination of the submission of proponents of universal sociology in the light of socio-economic and political developments in Third World countries, the aftermath of the collapse of bipolar politics and the adoption of neo-liberal economic principles and doctrine worldwide, negates the assertion that the people of the world are incorporated into a single world society. The idea of common humanity of a world in which people speak to people in peace and friendship and of universal reason does not exist in reality. According to Nyamnjoh (2004:51), "Globalisation is intensifying the divisions between...the north and the south and then within different countries of the north and the south". The Human Development Report 1999 (cited in Hong 2000:4) notes, inter alia, the following trends in this era of globalisation:

- More than 80 countries still have per capita incomes lower than they were a decade or more ago.

- The income gap between the world's richest fifth and its poorest fifth has more than doubled to 74 to 1 over the past three decades

- Debt servicing for the 41 poorest countries amounted to $\$ 11$.1billion in 1996

- Out of 50million migrants that are women the world over, 30 million are found in the Third World.

- 95 percent of all HIV infected victims are found in the Third World.

The implication of the above is that globalisation has led to increased migration; marginalisation of local communities; malnutrition; the disempowerment of nation states and the collapse of their economies. Governments in most Third World countries are burdened with debt and economic decline which make it almost impossible to achieve any meaningful social development for their peoples (see Hong, 2000). Khor corroborated the above when he opined that "globalisation is a very uneven process, with unequal distribution of benefits and losses. This imbalance leads to polarisation between the few countries...that gain, and the many countries and groups in society that loses out or are marginalised..."(Khor, 2005:9). There is equally a chasm that exists between the rich and the poor and this keeps expanding due to serious economic crisis that has pervaded the globe. The sociological implication of this is that it is not possible for people in different socioeconomic divide to conceptualise and interpret events in similar ways. What is more, human experience is differentiated by time, place, social identity and prevailing socio-economic conditions, among others. 
The call to jettison relativism of concepts, percept, meaning and so on because major aspects of social reality is simultaneously undergoing uniformisation due to the impact of globalisation has ontological and methodological implications for research, development policies and even various intervention programmes of international organisations such as the World Bank, International Monetary Fund (IMF), and so on. First, every human society is endowed with shared meaning of actions, institutions, roles which certainly are not the same in all human societies. Second, social reality, therefore, has a specific structure, meaning and relevance for the human beings living and interacting with others in such human society. Thus, according to Schutz (1975:273):

The thought objects constructed by the social scientist, in order to grasp social reality have to be founded upon the thought objects constructed by the... thinking of men, living their daily life within their social world. Thus the constructs of the social sciences are, so to speak the constructs of the second degree, namely constructs of the constructs made by the actors on the social scene, whose behaviour the social scientist has to observe and explain in accordance with the procedural rules of his science.

Because the position of proponents of universal sociology is the kind of mentality that the World Bank, the International Monetary Fund (IMF) and other Western Institutions have perpetrated around third world countries, their programmes have failed both in thought, in implementation and in outcome. With specific reference to Africa, Kiawi and Mfoulou (2002) assert that empirical evidence shows that the injection of loans, aids and other types of assistance to Africa has not really achieved much because of the outright disregard and lack of consideration for the culture of the African people (see Pitt, 1976). It can be argued that the adoption of western models of development and their integration with socio-economic realities in third world societies without a concomitant indigenous appraisal of the veracity of such models have created more problems than it has solved.

The neo-liberal doctrine of globalisation together with its reforms becomes more of rhetoric than reality as global capital is privileged to the detriment of labour. While capital is enabled to seek competitive advantage and the most secure and largest returns by roaming the globe for cheap but efficient production locations, labour is denied the same privilege. As labour move around in search of the most lucrative jobs, they become strangers in strange lands. Thus, the accelerated flow of capital, goods, electronic information and migration of labour across borders induced by globalisation have only exacerbated insecurities, uncertainties and anxieties among locals and foreigners alike. In the wake of globalisation has come greater crisis of settlers indigeneship differences which have resulted to xenophobia and related intolerance not only currently in South Africa but also in Europe where there 
are resurgences of anti-Semitic and racist attitudes. Therefore, globalisation appears to accelerate the production of differences, heterogeneities or boundaries through the structure of inequalities inherent in global capitalism. Hence global markets undermine social order (See Nyamnjoh, 2004; Osaghae, 2004). According to Sule (2006:12):

Today, there is a resurgence of cultural identities as a counter to the neo-cultural imperialism that has accompanied globalisation. For fear of going into 'extinction' various groups are repositioning themselves within the global milieu...the implication of these...for research...is that social scientists cannot 'wish away' the perception and world views of such groups.

The 'advice' that sociologists should jettison relativism of concepts because it breeds 'other minds' in a globalised world should be discarded by Third World sociologists and scholars, because it is a ploy to foist western system of thought, outlook (world view) approach and practice on the Third World as the best way of achieving progress, socio-economic and political development. The convergence of economic thinking and policy, including the homogenisation of culture which the world is witnessing today, is made possible by the electronic media of Cable News Network (CNN), British Broadcasting Corporation World (BBCW), EuroNews, France 24, etc. Their objective is not only to control global market, but also global consciousness. Through these frameworks, versions of Western cultures have been subtly forced on Third World peoples. Thus, while Third World scholars are invited to break free of 'world views' that are informed by their cultures of origin, the West/America under the garb of globalisation pushes a hegemonic mode of social life and organisation of European origin on the entire world.

\section{Conclusion}

This paper has argued that globalisation and the various neo-liberal reforms have not integrated nor transformed the world into a 'single world society'. Rather globalisation has intensified polarisation, divisions, differences between the developed and Third World countries on the one hand, and, has created more dependency that is characterised by unequal exchange on the other hand. What then should be the role of social science scholars, especially sociologists, from the Third World?

First, they should keep abreast of global trend of events, be sensitive to the various processes of social change that are taking place globally, and be ready to generate knowledge and consciousness through painstaking research in all spheres of human endeavour with findings that will, among others, defend the Third World against the insensitivity of the developed world (especially Western Europe/America).

Second, it is high time received Western paradigms was jettisoned in sociology (including the call for a universal sociology) and replaced with a 
Third World perspective, i.e. Sociology of Third World. It is from this platform that analysis should be drawn. Third World Scholars should also nationalise and localise, but 'do' research in the light of the unequal exchange relationship that exist between the Third World and the first and second worlds.

Finally, it is imperative to strengthen the Third World's think tank capacity. In a globalised world, key decisions affecting Third World countries are taken through international processes, conferences and complex multilateral negotiations. However, unlike the developed world, the third world lacks careful preparation, in-depth research, baseline data and coordinating mechanisms. The problem is further compounded by lack of political commitment on the part of their leaders because they are not even well informed. According to Khor (1995:16) "The G-77 lacks a research facility or a permanent secretariat and is unable to carryout long-term planning or strategising for international meetings and negotiations".

This is indeed where the Nigerian Anthropological and Sociological Association (NASA) can take the lead in championing and pace-setting a Third World Conference of sociologists and anthropologists (which should thereafter become a yearly event) on topical issues that directly or indirectly affect Third World countries. The findings that come from such conferences can become essential data that leaders from Third World countries can utilise as they negotiate terms with the developed nations or as they reconstruct their countries in the face of globalisation. In the same vein, such conferences can serve as a forum through which collaborative research work can commence in different and diverse dimensions of sociological inquiry such as the environment, education, population, nutrition, and effect of World Bank policies on the economy, etc. Such networking with other intellectual bodies would help in salvaging the Third World, or in the words of Roy:

...The way the third world is drifting today resembles a journey without a compass...they are off on a voyage across uncharted seas, bound for a land they don't know...The maps the third world countries are using today have become obsolete. Things are no longer what they used to be...time has come to revise the existing political cartography" (1999:107). 


\section{References}

Adesina, J.O. 2000. 'Sociology and Yoruba Studies: Epistemic Intervention or Doing Sociology in the Vernacular'?' Journal of the Nigerian Anthropological and Sociological Association, Special Edition 2000, pp. 253 277.

Akiwowo, A. 1988. Indigenisation of the Social Sciences and Emancipation of Thought. A Valedictory Lecture delivered at the Obafemi Awolowo University, Ile-Ife (Mimeograph).

Alatas, S.F. 2002. 'The Study of Social Sciences in Developing Countries: Towards Adequate Conceptualisation of Relevance' The Nigerian Social Sciences, 5(1): 15 - 24.

Albrow, M. and E. King. 1990. (eds.) Globalisation, Knowledge and Society: Readings from International Sociology. London: Sage Publication.

Archer, M.S. 1990. 'Resisting the Revival of Relativism' In M. Albrow \& E. King (eds.) (1990) Knowledge and Society: Readings from International Sociology, London: Sage Publication, pp. 19 - 34.

Beynon, J and D. Dunkerley, 2002 (eds.) Globalisation: The Reader. London: The Athlone Press.

Cohen, R and P. Kennedy 2000. Global Sociology. London: Macmillan.

Durkheim, E. 1938. The Rules of Sociological Method. New York: Free Press.

Giddens, A. 1990. The Consequences of Modernity. Cambridge: Polity Press.

Gulbenkian Commission 1996. Open the Social Sciences: Report of the Gulbenkian Commission on Restructuring of the Social Sciences. Standford: Standford University Press.

Harvey, D. 1989. The Condition of Post Modernity. Oxford: Basil Blacknell.

Held, D. 2000 (ed.). A Globalizing World? Culture, Politics, Economics. London: Sage Publication.

Heller, A. 1990. 'Sociology as the Defetishisaton of Modernity.' In M. Albrow \& E. King (eds.) Knowledge and Society: Readings from International Sociology. London: Sage Publication, pp. 35 - 45.

Hong, E. 2000. Globalisation and the Impact on Health: A Third World View. Third World Network 228, Macalister Road 10400, Penang.

Khor, M. 1995. 'Globalisation and the Need for Coordinated Southern Policy Response', In Cooperation South. New York, May 1995.

Khor, M. 2005. Globalisation and the South: Some Critical Issues. Ibadan: Spectrum Books Limited, (Reprinted Version).

Kiawi E.C. and J. Mfoulou, 2002. 'Rethinking African Development: Social Sciences Perspective'. CODERSRIA Bulletin, No. 1 \& 2; 12 - 17.

Lawuyi, O.B. and F. Taiwo, 1990. 'Towards an African Sociological Tradition: A Rejoinder to Akiwowo and Makinde'. In M. Albrow \& E. King (eds.) (1990), Knowledge and Society: Readings from International Sociology. London: Sage Publication, pp.135 - 154.

Nkom, S.A. 1993. 'Competing Paradigms in the Search for more Relevant Social Science in Nigeria' Journal of Third World. Vol. X (1):196 - 224. 
Nyamnjoh, F.B. 2004. 'Globalisation, Boundaries and Livelihoods: Perspectives on Africa', CODESRIA Bulletin, Vol. 5, 1 \& 2; pp. 37 - 60.

Osaghae, E. E. 2004. 'Introduction: Globalisation Diversity and Citizenship', CODESRIA Bulletin, Vol. 5, No. 1 \& 2: i - vii.

Pitt, D.C. 1976. Development from Below: Anthropologists and Development Situation. USA: Mouton Publishers.

Roy, A.N. 1999. The Third World in the Age of Globalisation: Requiem or New Agenda, London and New York: Zed Books.

Schutz, A. 1975. On Phenomenology and Social Relations. Chicago: University of Chicago Press.

Sule, I.D. 2006. Wither the Social Sciences in Africa in the $21^{\text {st }}$ Century: An Assessment of the Gulberkian Commission Report. Unpublished Paper Presented at the Zaria Conference on Humanities in Africa in the $21^{\text {st }}$ Century. Problems and Prospects, 10 - 14 January 2006.

Sztompka, P. 1990. 'Conceptual Framework in Comparative Inquiry: Divergent and Convergent'. In M. Albrow \& E. King (eds.). Globalisation, Knowledge and Society: Readings from International Sociology. London: Sage Publication, pp. $47-60$.

Tiryakian, E.A.1990. 'Sociology's Great Leap Forward: The Challenge of Internationalisation.' In M. Albrow \& E. King (eds.). Globalisation, Knowledge and Society: Readings from International Sociology. London: Sage Publication, pp. $63-78$.

Wallerstein I. 1990. 'Social Development or Development of the World System'. In M. Albrow \& E. King (eds.). Globalisation, Knowledge and Society: Readings from International Sociology. London: Sage Publication, pp. $157-171$. 